\title{
Assessment of Elder \\ Mistreatment in Two \\ American Indian
}

Samples: Psychometric

Journal of Applied Gerontology

2014, Vol. 33(3) 336-356

(c) The Author(s) 2013

Reprints and permissions:

sagepub.com/journalsPermissions.nav

DOI: 10.1 I77/07334648I2470748

jag.sagepub.com

(SAGE

Characteristics of the HS-

EAST and the Native Elder

Life-Financial Exploitation

and-Neglect Measures

\section{Lori L. Jervis' 'Alexandra Fickenscher ${ }^{2}$, Janette Beals ${ }^{2}$, and the Shielding American Indian Elders Project Team}

\begin{abstract}
Although elder mistreatment among ethnic minorities is increasingly gaining attention, our empirical knowledge of this phenomenon among American Indians remains quite limited, especially with respect to measurement. The Shielding American Indian Elders (SAIE) Project used a collaborative approach to explore culturally informed measurement of elder mistreatment in two American Indian elder samples (a Northern Plains reservation and a South Central metropolitan area). The project sought to investigate the performance characteristics of the commonly used Hwalek-Sengstock Elder Abuse Screening Test (HS-EAST), as well as to examine the psychometric properties of a new measure developed to capture culturally salient aspects of mistreatment in American Indian contextsthe Native Elder Life Scale (NELS). Using methods and samples comparable to
\end{abstract}

Manuscript received: February 17, 20I2; accepted: November 3, 2012.

'University of Oklahoma, Norman, OK, USA

${ }^{2}$ University of Colorado, Aurora, CO, USA

Corresponding Author:

Lori L. Jervis, University of Oklahoma, 3100 Monitor Avenue, Room 100, Norman, OK 7307I, USA.

Email: lori.jervis@ou.edu 
those in the literature, the HS-EAST performed adequately in these Native samples. The NELS also shows promise for use with this population and assesses different aspects of elder mistreatment than does the HS-EAST.

\section{Keywords}

American Indian, financial exploitation, elder abuse, measurement, HS-EAST

Elder mistreatment among ethnic minorities is gaining deserved attention among scholars and care providers (Moon, 2000; Moon \& Williams, 1993; Moulton et al., 2005; Simpson, 2005; Talamantes, McCorkle, \& Burge, 2005; Tatara, 1999). Our empirical knowledge of elder mistreatment among American Indians, however, remains limited (Benson, Nerenberg, \& Baldridge, 2004; Buchwald, Tomita, Ashton, Furman, \& Manson, 2000; Carson, 1995; Holkup, Salois, Tripp-Reimer, \& Weinert, 2007; Hudson, Armachain, Beasley, \& Carlson, 1998; Hudson \& Carlson, 1999; Jervis \& and the Shielding American Indian Elders Project Team, 2009; Nerenberg, Benson, \& Baldridge, 2004). This is especially true with respect to measurement issues. We know almost nothing about the adequacy of existing elder mistreatment measures in assessing either actual abuse or vulnerability to such abuse. Also unexplored is whether problems with the cultural relevance of existing tools might necessitate the development of new measures to capture culturally salient features of poor treatment of elders in these communities. This study, the Shielding American Indian Elders (SAIE) Project, examined these issues using a collaborative approach, with the goal of increasing knowledge about the appropriate measurement of the mistreatment of Native elders.

Using the survey data from SAIE, this article sought to address three research questions. First, we sought to understand the performance characteristics of an established measure, the Hwalek-Sengstock Elder Abuse Screening Test (HS-EAST), in two American Indian elder samples. A second question centered on the psychometric properties of a new measure developed by the SAIE Team. In particular, after the project team reviewed the HS-EAST, two aspects of Native elder abuse were considered inadequately assessed for this population by this measure: Financial Exploitation and Neglect. The Native Elder Life Scale (NELS) was developed to assess both these dimensions, with items selected and worded to culturally resonate in Native communities. Third, the study investigated the relationships of the HS-EAST and NELS to a commonly used outcome measure: health-related quality of life (Ware, 1994). In addressing these questions, we provide critical preliminary data on the reliability and validity of both the HS-EAST, a common risk measure of probable elder abuse, as well as the 
NELS, a unique measure of elder mistreatment in samples deriving from a population for which little data are available-American Indian elders.

\section{Method}

\section{Setting and Samples}

Funded by a National Institute on Aging developmental grant intended to improve the measurement of elder abuse, we interviewed 100 Native elders age 60 years and older from two data collection sites, 50 from a tribal senior center on a Northern Plains reservation and 50 from two Protestant Indian churches in an urban area in the South Central region of the United States. All but 2 of the 50 participants from the Northern Plains reservation were tribal members of that particular reservation, whereas the participants from the urban area were pantribal, belonging to 17 different tribes. Participants were chosen purposively, recruited by Native research staff who identified interested individuals at the respective field sites; subsequent participants were identified via snowball sampling based on recommendations from initial participants. Prior to beginning the data collection, formal approvals were received from the institutional review board of the Northern Plains tribe, the overseeing organization of the Protestant Indian churches, and institutional review board of the University of Oklahoma (OUIRB \#12390).

\section{Data Collection}

This collaborative project followed several principles of Community Based Participatory Research, which promotes the involvement of communities in all stages of the research process (Jones \& Wells, 2007; Minkler, Blackwell, Thompson, \& Tamir, 2003; Salois, Holkup, Tripp-Reimer, \& Weinert, 2006; Wallerstein \& Duran, 2006), including problem identification, project design, and data collection, analysis, interpretation, and dissemination. A key aspect of this effort was collaboration between two groups, who together comprised the project team: (a) a culturally and geographically diverse panel of 13 community experts with backgrounds in Native elder advocacy and abuse intervention, all but one of whom were themselves tribal members and (b) an interdisciplinary team of 6 investigators with research expertise in American Indian communities. The collaboration included elements such as revisiting as a group whether the project should be done at all, collaboration on the goals and design of the project, review of available measures and modification as necessary for cultural relevance, project team selection of data collection sites, employment of a community expert as a key research staff member in one of the communities, opportunities 
for collective interpretation of results, review of publications and group authorship, dissemination of project results, and continued involvement with participating communities (Jervis \& and the Shielding American Indian Elders Project Team, 2009).

\section{Measures and Covariates}

The survey that was administered to participants by Native research staff included not only the measures of elder mistreatment but also health-related quality of life and demographics. A number of open-ended questions allowed for further exploration of elders' conceptualizations of mistreatment.

Hwalek-Sengstock Elder Abuse Screening Test (HS-EAST). One of the few established measures of elder abuse, the HS-EAST was developed as a short screening measure to identify those at high risk for abuse, neglect, or exploitation (Hwalek $\&$ Sengstock, 1986). This 15 -item scale asks a series of yes/no questions about characteristics of elder vulnerability (e.g., sad/lonely, inability to get around by oneself), situations with potential for abuse (little privacy at home, family members drinking a lot), and violations of personal rights or abuse (forced to do things they did not want to do, taken things without OK). The HS-EAST has been shown to correctly identify $75 \%$ of known cases of elder abuse from matched controls (Neale, Hwalek, Scott, Sengstock, \& Stahl, 1990). In one study, a score of 3 or higher, out of a possible 9, comprised a valid measure of risk for abuse, neglect, or exploitation (Neale, Hwalek, Scott, Sengstock, \& Stahl, 1991).

The SAIE project team review of the HS-EAST resulted in one change. The question "Can you take your own medication and get around by yourself?" was broken out into two questions in order to increase comprehension; such changes are commonly suggested in measure adaptation for American Indian populations (Beals, Manson, Mitchell, Spicer, \& and the AI-SUPERPFP Team, 2003). For the purposes of the present analyses where comparisons to the published literature are being made, the answers to these questions were combined such that a "yes" to either the question about medication or mobility resulted in a "yes" for the combined item. As is typical with the HS-EAST, where necessary, responses were reversed coded so that a high score indicated possible abuse.

The HS-EAST was introduced as follows:

Now we are going to ask you some questions about things that sometimes happen to elders. In some of these questions, we use the term "family." By family, we mean anyone who you consider a family member. Family may also include a romantic partner or spouse. It may also include a caregiver who is not related to you. 
The definition of family was purposefully left broad to capture American Indian notions of kinship that may differ from dominant cultural constructions of family.

Native Elder Life Scale (NELS). This measure was developed to fill perceived gaps in financial exploitation and neglect items that captured the experience of Native people living in both urban and rural communities.

NEL-Financial Exploitation (NELS-FE). In a series of meetings among the project team, it was noted that some of the common items on existing financial exploitation measures (e.g., banking scams, manipulation of wills) make little sense in the Native context, whereas other forms are highly salient in these communities (e.g., excessive and coercive childcare, abuse of an elder's housing, theft of relatively small amounts of cash) are not typically assessed. The Financial Exploitation items were derived from such discussions among the SAIE project team. To develop these questions, community experts wrote questions that they themselves would ask if they were trying to determine whether an elder had been mistreated. Using those questions as a base, the researchers developed a new measure designed to capture these aspects of Native elder mistreatment. This instrument was field tested with a small group of older American Indians to determine if changes were needed. The modified measure was reviewed by the project team and further adjustments were made.

Originally containing 26 items, example questions included the following: "I know how much money I have," "My family depends on my money to make ends meet," and "I'm afraid to talk about money with my family." Responses options were "never," "sometimes," "usually," and "always," with "not applicable" as an additional category.

Three sets of items were conditional on the endorsement of a previous question. For instance, only those answering "sometimes," "usually," or "always" to "I need help paying my bills" were then asked "Someone makes sure my bills are paid on time," with bills not being paid on time considered a possible indication of financial exploitation. The other conditional questions focused on babysitting and raising children - only those who indicated they at least sometimes babysat or were the primary caretaker of children in the family were then asked whether these activities were financially or physically difficult or were expected of them. Those who interpreted these activities as nonproblematic or even positive were considered not exploited with regard to that activity. In these cases, responses to the items were combined in such a way that a "l" indicated that the potential vulnerability did not exist (e.g., others paying bills, babysitting, or raising children) or - if the vulnerability existed - no exploitation occurred (e.g., the bills were paid on time or babysitting was not a hardship). The additional response categories, then, indicated both that the vulnerability existed and provided 
information on the frequency to which problems occurred (sometimes, usually, or always). For the babysitting and raising children questions, a mean score of the problems was calculated and then recategorized into scores of 1 to 4 . Once this logical data reduction was completed, 18 items remained in the financial exploitation scale. Where necessary, the responses were reverse coded so that a high score indicated possible exploitation.

NELS-Neglect. The second important dimension of elder mistreatment suggested by the SAIE project team was neglect. Also generated through group review of the items by the project team, the 12 items include questions such as "My family respects me," "I am left alone when I need help," and "I'm afraid I'll be left alone if I ask for what I want." As with financial exploitation, the four response options ranged from "never" to "always," with "not applicable" also available. Where necessary, the responses were reverse coded so that a high score indicated possible neglect.

The introductory statements for the NELS mirrored those of the HS-EAST.

Demographic measures. Included in the analyses are dichotomous measures coded 0/1 with 1 indicating member of the South Central sample, female gender, married or living together, working now, some post-high school education, speaks tribal language at least moderately well, and receives financial assistance (restricted to Temporary Assistance for Needy Families [TANF], Supplemental Security Income [SSI], food stamps, and disability). Also included were continuous measures of age and number of people living in the participant's home.

Medical Outcomes Study Short-Form-I2 (SF-I2). The SF-12 is an established measure of health-related quality of life. Based on the SF-36, which has been shown to have adequate reliability and validity in other American Indian elder samples (Beals et al., 2006), the SF-12 is a multidimensional assessment of both physical and mental health functioning. The 12 items are summarized by two summary scales, the Physical and Mental Component Summaries (PCS and MCS, respectively), which are constructed to be uncorrelated and normed, using a national probability sample, to have a mean of 50 and standard deviation of 10 for adults. In the SAIE Project sample, Cronbach's alpha for the SF-12 was .88. The PCS and MCS were used as outcomes in the regression analyses reported here.

\section{Analytic Strategy}

Analyses were conducted using IBM SPSS Statistics, Version 19 (IBM, 2010). Assessment of statistical significance across samples was derived from $\chi^{2}$ analyses for categorical and ordinal variables and $t$ tests for continuous variables. 
Item-level statistics are provided for the HS-EAST, NELS-Financial Exploitation, and NELS-Neglect measures. Mean scores included those items for which variability was seen across samples and for those cases in which at least half of the item-level data were present. Although not ideally powered for factor analysis, exploratory principal components analyses allowed for a better understanding of the dimensionality of the scales. The summary scale statistics include Cronbach's alpha and means; for the HS-EAST, a count of affirmative responses is also provided together with the percentage of the sample with a count of 3 or higher.

Multiple regression was used to assess the relationships among the demographic and mistreatment measures with both the PCS and MCS of the SF-12. Initially, the bivariate relationship of each demographic and mistreatment measure to the PCS and MCS were assessed; those demonstrating a beta significant at the $p<.10$ level were included in the final multiple regression equation. The possibility of interactions between sample (Northern Plains and South Central) and the other predictors in the final multiple regressions was assessed; none attained statistical significance and are, thus, not presented. Throughout, only those statistical tests significant at $p<.05$ are discussed.

\section{Results}

The sample characteristics may be found in Table 1. Half of the total sample was derived from the Northern Plains $(n=50)$ and half from the South Central group $(n=50)$. The participants were predominantly women; most were married, and the majority had some post-high school education. About a quarter were working at the time of interview and $17 \%$ received financial assistance (TANF, SSI, food stamps, and/or disability). About a quarter spoke their tribal language at least moderately well. The mean age was 70 years. The average SF-12 PCS score was 41.9, with the MCS mean score being 51.8; as expected, these measures were uncorrelated $(r=.036, p=.726)$ in these samples. On average, participants reported that 2.4 people resided in their homes. Almost one third $(31 \%)$ of the Northern Plains participants were living with children under the age of 18 years compared with $6 \%$ of South Central elders $(p<.002)$. Those from the Northern Plains were more likely than their South Central counterparts to have more people living in the home and to be employed.

Table 2 presents summary information about the HS-EAST. Missing data were uncommon with the exception of the question "Do you feel uncomfortable with anyone in your family"; 6 of the 100 participants did not answer this question, interestingly all 6 lived with others. The most commonly endorsed items concerned the unavailability of someone to help the elder (65\%), the need for the 
Table I. Demographic Description of Shielding American Indian Elder Samples.

\begin{tabular}{|c|c|c|c|c|c|c|c|c|}
\hline & \multicolumn{2}{|c|}{$\begin{array}{c}\text { Total } \\
(N=100)\end{array}$} & \multicolumn{2}{|c|}{$\begin{array}{l}\text { Northern Plains } \\
\quad(n=50)\end{array}$} & \multicolumn{2}{|c|}{$\begin{array}{l}\text { South Central } \\
\qquad(n=50)\end{array}$} & \multicolumn{2}{|l|}{$\chi^{2}$} \\
\hline Women & \multicolumn{2}{|c|}{$72 \%$} & \multicolumn{2}{|c|}{$66 \%$} & \multicolumn{2}{|c|}{$78 \%$} & \multicolumn{2}{|l|}{1.79} \\
\hline Currently married & \multicolumn{2}{|c|}{$52 \%$} & \multicolumn{2}{|c|}{$56 \%$} & \multicolumn{2}{|c|}{$48 \%$} & \multicolumn{2}{|l|}{0.64} \\
\hline Working now & \multicolumn{2}{|c|}{$27 \%$} & \multicolumn{2}{|c|}{$40 \%$} & \multicolumn{2}{|c|}{$14 \%$} & \multicolumn{2}{|c|}{$8.60 * *$} \\
\hline $\begin{array}{l}\text { Post-high school } \\
\text { education }\end{array}$ & \multicolumn{2}{|c|}{$63 \%$} & \multicolumn{2}{|c|}{$62 \%$} & \multicolumn{2}{|c|}{$64 \%$} & \multicolumn{2}{|c|}{0.04} \\
\hline $\begin{array}{l}\text { Speaks tribal language at } \\
\text { least moderately well }\end{array}$ & \multicolumn{2}{|c|}{$26 \%$} & \multicolumn{2}{|c|}{$20 \%$} & \multicolumn{2}{|c|}{$32 \%$} & \multicolumn{2}{|l|}{1.90} \\
\hline \multirow{2}{*}{$\begin{array}{l}\text { Receives financial } \\
\text { assistance }\end{array}$} & \multicolumn{2}{|c|}{$17 \%$} & \multicolumn{2}{|c|}{$16 \%$} & \multicolumn{2}{|c|}{$18 \%$} & \multicolumn{2}{|c|}{0.07} \\
\hline & Mean & $S D$ & Mean & $S D$ & Mean & $S D$ & $t$ & $d f$ \\
\hline Age & 70.0 & 6.8 & 69.4 & 5.4 & 70.6 & 8.0 & 0.90 & 98 \\
\hline $\begin{array}{l}\text { Number of people in } \\
\text { home }\end{array}$ & 2.4 & 1.2 & 2.7 & 1.5 & 2.1 & 0.8 & $2.73 * *$ & 98 \\
\hline $\begin{array}{l}\text { SF-I } 2 \text { Physical Component } \\
\text { Summary }\end{array}$ & 41.9 & 10.7 & 43.7 & 10 & 40 & 11.2 & 1.74 & 94 \\
\hline $\begin{array}{l}\text { SF-I } 2 \text { Mental Component } \\
\text { Summary }\end{array}$ & 51.8 & 10.5 & 49.9 & 11.4 & 53.6 & 9.2 & 1.72 & 94 \\
\hline
\end{tabular}

$*_{p}<.05 . * * p<.01 . * * * * 0.001$.

elder to support others (42\%), and family members drinking to excess $(35 \%)$. On the other hand, physical abuse (1\%), forced bed rest (2\%), lack of privacy (3\%), theft (4\%), and being told they gave others "too much trouble" (4\%) were quite uncommon. Differences between the two samples occurred in 6 of the 15 items; in each case, the Northern Plains sample was more likely to indicate higher risk than were those from the South Central sample. Using the Kaiser criterion, an exploratory factor analysis indicated the existence of a strong primary and relatively weak secondary factor, with the latter composed of only two items (someone spends time with you and someone in family drinks a lot). Supported by these findings and as is common with the HS-EAST, a single summary measure was constructed. Cronbach's alpha was .67 for the Northern Plains sample but only .59 for those from the South Central group. Examination of the item-total correlations indicated that the item "Who makes decisions about your life?" operated differently in the two samples, with corrected item-total correlations .016 for the Northern Plains and -.242 for the South Central samples. Because of these disparate findings, this item was deleted from the scale. As would be expected, the Northern Plains sample had a significantly higher mean HS-EAST score as well 
Table 2. HS-EAST Item-Level and Scale-Level Summaries.

\begin{tabular}{|c|c|c|c|c|c|c|}
\hline & $n$ & $\begin{array}{l}\text { Final } \\
\text { scale }\end{array}$ & Total & $\begin{array}{l}\text { Northern } \\
\text { Plains }\end{array}$ & $\begin{array}{l}\text { South } \\
\text { Central }\end{array}$ & $\chi^{2}$ \\
\hline $\begin{array}{l}\text { Do you have anyone who spends } \\
\text { time with you, taking you } \\
\text { shopping or to the doctor? } \\
\text { (Reversed) }\end{array}$ & 99 & $*$ & $65 \%$ & $78 \%$ & $51 \%$ & $7.88^{* *}$ \\
\hline $\begin{array}{l}\text { Are you helping to support } \\
\text { someone? }\end{array}$ & 100 & $*$ & $42 \%$ & $52 \%$ & $32 \%$ & $4.10 *$ \\
\hline Are you sad or lonely? & 98 & $*$ & $24 \%$ & $26 \%$ & $21 \%$ & 0.36 \\
\hline $\begin{array}{l}\text { Who makes decisions about } \\
\text { your life-Like how you should } \\
\text { live or where you should } \\
\text { live? (Someone else making } \\
\text { decisions indicates risk) }\end{array}$ & 100 & & $33 \%$ & $48 \%$ & $18 \%$ & $10.18^{* * *}$ \\
\hline $\begin{array}{l}\text { Do you feel uncomfortable with } \\
\text { anyone in your family? }\end{array}$ & 94 & $*$ & $15 \%$ & $18 \%$ & $12 \%$ & $0.7 \mathrm{I}$ \\
\hline $\begin{array}{l}\text { Can you take your own } \\
\text { medication and/or get around } \\
\text { by yourself? ( } 2 \text { items combined } \\
\text { and then reversed) }\end{array}$ & 100 & $*$ & $3 \%$ & $6 \%$ & $0 \%$ & 3.09 \\
\hline $\begin{array}{l}\text { Do you feel that nobody wants } \\
\text { you around? }\end{array}$ & 99 & $*$ & $13 \%$ & $22 \%$ & $4 \%$ & $6.97 * *$ \\
\hline $\begin{array}{l}\text { Does anyone in your family } \\
\text { drink a lot? }\end{array}$ & 100 & $*$ & $35 \%$ & $48 \%$ & $22 \%$ & $7.43^{* *}$ \\
\hline $\begin{array}{l}\text { Does someone in your family } \\
\text { make you stay in bed or tell you } \\
\text { you're sick when you're not }\end{array}$ & 100 & $*$ & $2 \%$ & $4 \%$ & $0 \%$ & 2.04 \\
\hline $\begin{array}{l}\text { Has anyone forced you to do } \\
\text { thing you didn't want to do? }\end{array}$ & 100 & $*$ & $4 \%$ & $2 \%$ & $6 \%$ & 1.04 \\
\hline $\begin{array}{l}\text { Has anyone take things that } \\
\text { belonged to you without your } \\
\text { OK? }\end{array}$ & 100 & $*$ & $24 \%$ & $32 \%$ & $16 \%$ & 3.51 \\
\hline $\begin{array}{l}\text { Do you trust most of the people } \\
\text { in your family? (Reversed) }\end{array}$ & 100 & $*$ & $11 \%$ & $18 \%$ & $4 \%$ & $5.01 *$ \\
\hline $\begin{array}{l}\text { Does anyone tell you that you } \\
\text { give them too much trouble? }\end{array}$ & 100 & $*$ & $4 \%$ & $4 \%$ & $4 \%$ & 0.00 \\
\hline $\begin{array}{l}\text { Do you have enough privacy at } \\
\text { home? (Reversed) }\end{array}$ & 100 & $*$ & $3 \%$ & $6 \%$ & $0 \%$ & 3.09 \\
\hline $\begin{array}{l}\text { Has anyone close to you tried to } \\
\text { hurt or harm you recently }\end{array}$ & 98 & & $1 \%$ & $0 \%$ & $2 \%$ & $\mathrm{Na}$ \\
\hline
\end{tabular}


Table 2. (continued)

\begin{tabular}{lcccccc}
\hline & & Final & & Northern & South & \\
& $n$ & scale & Total & Plains & Central & $\chi^{2}$ \\
\hline $\begin{array}{l}\text { Cronbach's } \alpha \text { (includes items } \\
\text { with *) }\end{array}$ & 90 & 0.74 & 0.67 & 0.59 & \\
$\begin{array}{l}\text { Mean of Final HS-EAST scale } \\
\text { (includes items with *) }\end{array}$ & 100 & 0.19 & 0.24 & 0.13 & $3.79 * * *$ \\
$\begin{array}{l}\text { Count of HS-EAST items } \\
\begin{array}{l}\text { Percentage at risk for abuse, } \\
\text { neglect, exploitation }\end{array}\end{array}$ & 100 & 2.43 & 3.14 & 1.72 & $3.69 * * *$ \\
\hline
\end{tabular}

Note. HS-EAST = Hwalek-Sengstock Elder Abuse Screening Test. Boldface indicates a significantly higher endorsement rate of the item among the Northern Plains sample compared to the Southcentral group.

$*_{p}<.05 . * * p<.01 . * * * p<.001$.

as a higher count of affirmative risk items than the South Central sample. Even with the deletion of one item, more than half of those from the Northern Plains sample had an HS-EAST score of 3 or higher compared with about a quarter of those from the South Central sample.

The NELS-Financial Exploitation items are presented in Table 3. Typically, participants averaged between "never" and "sometimes" in their responses. Little missing data were found. As explained above, three sets of conditional questions are present and highlighted in the table; for these, the resulting combined measures were used in the scale analyses. The questions with the highest reported means were "My family knows when I have money coming" and "My family depends on my money to make ends meet." The item "My family has made me sign documents that I don't want to sign" was not endorsed by anyone; 5 other items were endorsed by members of the Northern Plains sample but not by those from the South Central sample; these 6 items were deleted from the final summary scale. Of the 12 remaining items, sample differences were found for only 2 items. Exploratory factor analyses indicated a strong first factor suggesting a development of a single scale was appropriate. Cronbach's alpha was .75 for the Northern Plains and .53 for South Central; examination of both the reliability and factor analytic results failed to suggest approaches that would yield greater internal consistency for the latter sample. The mean scores of the resulting summary measure were not different across samples.

The NELS-Neglect items are presented in Table 4. Missing data were not a problem, although four participants chose "not applicable" for the item "I fell and no one helped me up"; three of these elders lived alone. The item with the highest mean score was the reverse coded version of "My family helps me with 
Table 3. Native Elder Life-Financial Exploitation Measure: Item-Level and ScaleLevel Summaries.

\begin{tabular}{|c|c|c|c|c|c|c|}
\hline & $n$ & $\begin{array}{l}\text { Final } \\
\text { scale }\end{array}$ & Total & $\begin{array}{l}\text { Northern } \\
\text { Plains }\end{array}$ & $\begin{array}{l}\text { South } \\
\text { Central }\end{array}$ & $\chi^{2}$ \\
\hline $\begin{array}{l}\text { I know how much money I have } \\
\text { (Reversed) }\end{array}$ & 100 & $*$ & 1.16 & 1.10 & 1.22 & 1.43 \\
\hline $\begin{array}{l}\text { I know when my money (or check) is } \\
\text { coming (Reversed) }\end{array}$ & 100 & $*$ & 1.16 & 1.02 & 1.30 & 3.53 ** \\
\hline $\begin{array}{l}\text { My family knows when I have money } \\
\text { coming }\end{array}$ & 99 & $*$ & 2.71 & 2.69 & 2.72 & 0.11 \\
\hline $\begin{array}{l}\text { My family depends on my money to } \\
\text { make ends meet }\end{array}$ & 100 & $*$ & 2.05 & 2.18 & 1.92 & I.II \\
\hline $\begin{array}{l}\text { My family uses my money for things } \\
\text { like alcohol or drugs }\end{array}$ & 99 & & 1.02 & 1.04 & 1.00 & 1.41 \\
\hline $\begin{array}{l}\text { My family uses my money for things } \\
\text { like gambling }\end{array}$ & 100 & $*$ & 1.13 & 1.10 & 1.16 & 0.68 \\
\hline $\begin{array}{l}\text { My family takes things from my home } \\
\text { without permission and sells or } \\
\text { pawns them }\end{array}$ & 99 & & 1.07 & 1.14 & 1.00 & $2.80 * *$ \\
\hline $\begin{array}{l}\text { My family has made me sign } \\
\text { documents that I don't want to sign } \\
\text { (like wills or other legal papers) }\end{array}$ & 100 & & 1.00 & 1.00 & 1.00 & \\
\hline I need help paying bills & 99 & & 1.29 & 1.26 & 1.33 & 0.50 \\
\hline $\begin{array}{l}\text { Someone helps make sure my bills } \\
\text { are paid on time (reversed) }\end{array}$ & 20 & & 2.20 & 3.44 & 3.18 & 0.51 \\
\hline $\begin{array}{l}\text { SUMMARY: I need help paying bills but } \\
\text { they are not paid on time }\end{array}$ & 99 & $*$ & 1.47 & 1.36 & 1.41 & 0.31 \\
\hline $\begin{array}{l}\text { My money is being used in the way I } \\
\text { want it used (Reversed) }\end{array}$ & 99 & $*$ & 1.27 & 1.20 & 1.35 & 1.10 \\
\hline $\begin{array}{l}\text { I'm afraid to talk about my money } \\
\text { with my family }\end{array}$ & 98 & $*$ & 1.37 & 1.38 & 1.35 & 0.16 \\
\hline $\begin{array}{l}\text { My family borrows money from me } \\
\text { and doesn't pay it back }\end{array}$ & 100 & $*$ & 1.36 & 1.44 & 1.28 & 1.28 \\
\hline $\begin{array}{l}\text { I have run out of things like food or } \\
\text { medicine by the end of the month } \\
\text { because my family uses it for other } \\
\text { things }\end{array}$ & 100 & $*$ & 1.01 & 1.02 & 1.00 & 1.00 \\
\hline $\begin{array}{l}\text { I have received "shut off" notices for } \\
\text { electricity, the phone, or other things } \\
\text { because my family uses by money for } \\
\text { other things }\end{array}$ & 100 & $*$ & 1.03 & 1.04 & 1.02 & 0.58 \\
\hline $\begin{array}{l}\text { My family has taken cultural regalia or } \\
\text { sacred items away from me }\end{array}$ & 100 & $*$ & 1.03 & 1.06 & 1.00 & 1.77 \\
\hline $\begin{array}{l}\text { My family has taken personal property } \\
\text { (like land or other material goods) } \\
\text { away from me }\end{array}$ & 100 & $*$ & 1.03 & 1.06 & 1.00 & 1.77 \\
\hline
\end{tabular}


Table 3. (continued)

\begin{tabular}{|c|c|c|c|c|c|c|}
\hline & $n$ & $\begin{array}{l}\text { Final } \\
\text { scale }\end{array}$ & Total & $\begin{array}{l}\text { Northern } \\
\text { Plains }\end{array}$ & $\begin{array}{l}\text { South } \\
\text { Central }\end{array}$ & $\chi^{2}$ \\
\hline I babysit for my children & 100 & & 1.53 & 1.50 & 1.56 & 0.38 \\
\hline $\begin{array}{l}\text { I babysit because I enjoy it } \\
\text { (Reversed) }\end{array}$ & 40 & & 1.73 & 2.00 & 1.42 & $2.18^{*}$ \\
\hline I babysit more than l'd like & 40 & & 1.30 & 1.29 & 1.32 & 0.17 \\
\hline Babysitting is hard on me financially & 40 & & 1.18 & 1.29 & 1.05 & 1.49 \\
\hline Babysitting is hard on me physically & 40 & & 1.60 & 1.43 & 1.79 & 1.49 \\
\hline $\begin{array}{l}\text { SUMMARY: I babysit for my children } \\
\text { and it is hard on me }\end{array}$ & 100 & $*$ & 1.53 & 1.52 & 1.54 & 0.13 \\
\hline $\begin{array}{l}\text { I am raising children in my family } \\
\text { (that is, I'm their primary } \\
\text { caretaker) }\end{array}$ & 100 & & 1.35 & 1.54 & 1.16 & $2.09 *$ \\
\hline $\begin{array}{l}\text { Raising children in my family is } \\
\text { financially hard on me }\end{array}$ & 14 & & 2.29 & 2.50 & 1.75 & 1.00 \\
\hline $\begin{array}{l}\text { Raising children in my family is } \\
\text { physically hard on me }\end{array}$ & 14 & & 1.93 & 2.20 & 1.25 & $2.67^{*}$ \\
\hline $\begin{array}{l}\text { My family expects me to raise } \\
\text { children in my family }\end{array}$ & 14 & & 2.07 & 1.00 & 1.75 & 0.58 \\
\hline $\begin{array}{l}\text { SUMMARY: I raise children and it is } \\
\text { hard on me and/or is expected }\end{array}$ & 100 & $*$ & 1.31 & 1.48 & 1.14 & $2.13^{*}$ \\
\hline Cronbach's $\alpha$ & 95 & & 0.65 & 0.75 & 0.53 & \\
\hline $\begin{array}{l}\text { Mean of financial exploitation items } \\
\text { (includes items with *) }\end{array}$ & 100 & & 1.33 & 1.32 & 1.32 & 0.44 \\
\hline
\end{tabular}

Note. Shaded cells indicate items that are conditional on one another and combined into summary measures.

$*_{p}<.05 .{ }^{* *} p<.01 .{ }^{* * *} p<.001$.

things I need," indicating that, on average, participants reported that sometimes their families did not help with their needs. No variability was found for two items in the Northern Plains sample ("My family keeps me from getting the help I need" and "I am afraid I will be left alone if I ask for what I want") and these items were deleted. Factor analyses suggested a strong first factor, with strong resulting Cronbach's alphas; thus, a single summary scale was constructed. No mean differences were found between the samples on this summary score.

These three indicators of elder mistreatment were significantly related with one another. The correlations between the HS-EAST and NELS-Financial Exploitation were .48 and .55 with NELS-Neglect; the two latter indicators had a correlation of 38 .

Table 5 presents the results of the regression analyses investigating the relationships between the demographic and mistreatment measures and the PCS and 
Table 4. Native Elder Life-Neglect Measure: Item-Level and Scale-Level Summaries.

\begin{tabular}{|c|c|c|c|c|c|c|}
\hline & $n$ & $\begin{array}{l}\text { Final } \\
\text { scale }\end{array}$ & Total & $\begin{array}{l}\text { Northern } \\
\text { Plains }\end{array}$ & $\begin{array}{l}\text { South } \\
\text { Central }\end{array}$ & $\chi^{2}$ \\
\hline My family respects me (Reversed) & 100 & * & 1.38 & $\mathrm{I} .40$ & 1.36 & 0.30 \\
\hline $\begin{array}{l}\text { I get a lot of emotional support } \\
\text { from my family (Reversed) }\end{array}$ & 100 & $*$ & 1.49 & 1.54 & $\mathrm{I} .44$ & 0.67 \\
\hline I am left alone when I need help & 100 & $*$ & 1.25 & 1.30 & 1.20 & 0.84 \\
\hline $\begin{array}{l}\text { I get enough to eat every day } \\
\text { (Reversed) }\end{array}$ & 100 & $*$ & 1.07 & 1.08 & 1.06 & 0.39 \\
\hline I have enough clothes (Reversed) & 100 & $*$ & 1.07 & 1.08 & 1.06 & 0.39 \\
\hline $\begin{array}{l}\text { My family helps me with things I } \\
\text { need (Reversed) }\end{array}$ & 97 & $*$ & 2.18 & 2.47 & 1.88 & $2.61 * *$ \\
\hline $\begin{array}{l}\text { My family keeps me from getting } \\
\text { the help I need }\end{array}$ & 100 & & 1.01 & 1.00 & 1.02 & 1.00 \\
\hline $\begin{array}{l}\text { I am afraid I'll be left alone if I ask } \\
\text { for what I want }\end{array}$ & 99 & & 1.02 & 1.00 & 1.04 & 0.99 \\
\hline $\begin{array}{l}\text { My family pays attention to me } \\
\text { (Reversed) }\end{array}$ & 100 & $*$ & 1.59 & 1.70 & 1.48 & 1.53 \\
\hline My family sees me a lot (Reversed) & 99 & $*$ & 1.82 & 1.86 & 1.78 & 0.48 \\
\hline $\begin{array}{l}\text { I need help keeping my home clean } \\
\text { and don't get it }\end{array}$ & 98 & $*$ & 1.09 & 1.02 & 1.16 & 1.70 \\
\hline I fell and no one helped me get up & 96 & $*$ & 1.44 & 1.47 & 1.41 & 0.36 \\
\hline Cronbach's $\alpha$ & 93 & & 0.78 & 0.80 & 0.78 & \\
\hline $\begin{array}{l}\text { Mean of Neglect items (includes } \\
\text { items with *) }\end{array}$ & 100 & & 1.43 & 1.49 & 1.38 & 1.38 \\
\hline
\end{tabular}

$*_{p}<.05 . * * p<.01 . * * * p<.001$.

MCS. Focusing on those bivariate relationships significant at the $p<.05$ level, we see that higher physical health-related quality of life was associated with currently working, whereas lower PCS scores were associated with speaking the tribal language and receiving financial assistance. Although the overall multivariate regression equation was statistically significant, none of the individual parameters were significant.

Turning to the MCS, fewer demographic variables were bivariately associated with mental health-related quality of life, although it is noteworthy that speaking the tribal language was positively related with higher MCS scores. Each of the mistreatment measures demonstrated a strong bivariate relationship with the MCS. The multiple regression equation explained $32.5 \%$ of the variability in the MCS, with the HS-EAST and NELS-Neglect scales continuing to demonstrate strong relationships with the MCS controlling for other variables in the equation. 
Table 5. Relationships with SFI2 PCS and MCS: Bivariate and Multivariate Regression Results.

\begin{tabular}{|c|c|c|c|c|}
\hline & \multicolumn{2}{|c|}{ PCS } & \multicolumn{2}{|c|}{ MCS } \\
\hline & Bivariate, $b$ & Multivariate, $b$ & Bivariate, $b$ & Multivariate, $b$ \\
\hline South Central sample & -0.177 & -0.109 & 0.175 & -0.002 \\
\hline Female & 0.111 & & -0.038 & \\
\hline Married & 0.109 & & -0.102 & \\
\hline $\begin{array}{l}\text { Post-high school } \\
\text { education }\end{array}$ & 0.192 & 0.135 & 0.033 & \\
\hline Working now & $0.236^{*}$ & 0.147 & -0.04 & \\
\hline $\begin{array}{l}\text { Speaks tribal language at } \\
\text { least moderately well }\end{array}$ & $-0.225^{*}$ & -0.146 & $0.207^{*}$ & 0.124 \\
\hline $\begin{array}{l}\text { Receives financial } \\
\text { assistance }\end{array}$ & $-0.23 I^{*}$ & -0.123 & -0.087 & \\
\hline Age at time of interview & -0.159 & & 0.003 & \\
\hline $\begin{array}{l}\text { Number of people living } \\
\text { at home }\end{array}$ & -0.014 & & -0.115 & \\
\hline HS-EAST & 0.067 & & $-0.524 * * *$ & $-0.305 * *$ \\
\hline $\begin{array}{l}\text { NELS-Financial } \\
\text { Exploitation }\end{array}$ & -0.169 & -0.158 & $-0.413^{* * * *}$ & -0.176 \\
\hline \multirow[t]{2}{*}{ NELS-Neglect } & $0.04 I$ & & $0.468 * * *$ & $-0.219 *$ \\
\hline & & $R^{2}$ & & $R^{2}$ \\
\hline $\begin{array}{l}\text { Summary of multivariate } \\
\text { regression }\end{array}$ & & $11.2 \% * *$ & & $32.5 \% * * * *$ \\
\hline
\end{tabular}

Note. HS-EAST = Hwalek-Sengstock Elder Abuse Screening Test; NELS = Native Elder Life Scale. $* p<.05 . * * p<.01 . * * * p<.001$.

\section{Discussion}

\section{Performance of the HS-EAST in These American Indian Samples}

The HS-EAST remains a standard in the field of elder abuse identification-both at the individual and population levels. Although the literature is somewhat sparse, two types of studies typify the HS-EAST literature. The first are validity studies where the psychometric qualities of the scale are assessed as is its ability to distinguish between known groups of abused and nonabused elders (Hwalek \& Sengstock, 1986; Moody, Voss, \& Lengacher, 2000; Neale et al., 1991). The second set of studies include population-based assessments of probable elder abuse, in particular the Women's Health Australia (WHA) study (Schofield \& Mishra, 2003; Schofield, Reynolds, Mishra, Powers, \& Dobson, 2002). Both types are useful in contextualizing the results reported here. 
Interestingly, although the HS-EAST is typically constructed as a unidimensional summary measure, factor analyses presented in several of the early studies found varying — and inconsistent—-factor structures (Hwalek \& Sengstock, 1986; Moody et al., 2000; Neale et al., 1991). Here, we found a single factor solution to fit these data adequately with Cronbach's alphas ranging from .59 to .74 , often higher than appearing elsewhere. As in many of the other HS-EAST studies, the sample size here is insufficient for conclusive factor analytic investigations. An important next step in understanding the psychometric properties of this scale would be an adequately powered confirmatory factor analytic study, in which appropriate estimation techniques for dichotomous data are used to contrast the fit of alternative models. Still, using methods and samples reasonably comparable to those in the literature, we can conclude that the HS-EAST performed adequately in these American Indian samples.

The WHA data (Schofield et al., 2002), on the other hand, provide the most comparable prevalence data, albeit with a sample of largely White Australian women, for the 10 items the two studies share in common. Whereas $24 \%$ of the American Indian elders in SAIE indicated that people were likely to take things without their OK, only $4 \%$ of the Australian women in the WHA endorsed this item. Similarly, the SAIE sample appears more likely (24\%) to endorse the items "Are you sad and lonely?" (15\% in WHA) and "Do you feel uncomfortable with anyone in your family?" ( $15 \%$ in SAIE and $8 \%$ in WHA). For these specific items, no significant differences were found between the two American Indian samples. A question arises, then, about whether these items are more prevalent in American Indian communities than among Australian women, are interpreted differently, or some combination thereof. On the other hand, for other questions, the Northern Plains sample had higher endorsement rates than either the South Central or WHA samples. For example, "Do you feel nobody wants you around?" was endorsed by $22 \%$ of the Northern Plains sample compared with $4 \%$ and $3 \%$, respectively, of the South Central American Indian sample or Australian sample. On average, the Northern Plains sample endorsed 1.3 of these 10 items compared with 0.6 and 0.7 items in the South Central and WHA samples, respectively. Although only suggestive, our results point to the need for further exploration of both the cultural validity and prevalence of the vulnerabilities assessed in the HS-EAST among American Indian elders.

\section{Need for and Performance of the Native Elder Life Scale}

In their review of the HS-EAST, the SAIE project team argued strongly that this measure did not adequately address important domains of elder mistreatment in American Indian communities. The resulting NELS-Financial Exploitation 
and NELS-Neglect scales developed using collaborative approaches show promise. As should be expected, given the early stage of scale development that the NELS represents, a certain number of items showed insufficient variability for inclusion in the final summary measures. Whether such questions would be useful in samples at higher risk for elder mistreatment is an open question.

As was the case with the HS-EAST, a single factor was the most efficient in summarizing the underlying dimensionality of the Financial Exploitation and Neglect scales. Again larger sample sizes would allow for more thorough investigations of factor structures. Interestingly, with these scales Cronbach's alphas were acceptable with the exception of the Financial Exploitation measure among the South Central elders. In contrast to the HS-EAST, the two samples did not differ in the mean scores on these two measures. Finally, although they are significantly correlated with the HS-EAST, the magnitude of these correlations yielded a maximum of $30 \%$ shared variance $\left(.55^{2}\right)$ - a strong indication that both assess different aspects of elder mistreatment than the HS-EAST.

Although the current study was not designed as a validation effort in which the ability of scales to differentiate known abused elders from nonabused could be tested, following the lead of Schofield et al. (2002), we tested the degree to which these measures predicted current health-related quality of life. One would anticipate that these measures would more closely align with the MCS than PCS. They did, supporting a conclusion of differential validity. Indeed, none of the elder mistreatment scales demonstrated either bivariate or multivariate relationships with the PCS. On the other hand, each of the HS-EAST, NELS-Financial Exploitation, and NELS-Neglect scales demonstrated strong bivariate relationships with the MCS. Controlling for each other and for demographic measures, the HS-EAST and Neglect scales continued to be related with the MCS; the Financial Exploitation scale was marginally related. These measures hold promise for use in American Indian elder populations and merit additional investigation with larger samples, allowing more sophisticated analytic approaches.

\section{Samples: Limitations, Strengths, and Inferences}

To our knowledge, this study represents the first quantitative investigation of elder mistreatment measurement among American Indians. At the same time, these samples represent only a small portion of the cultural diversity inherent in Native populations within the United States, where more than 650 American Indian tribes and Alaska Native villages are federally recognized (Bureau of Indian Affairs, 2009), not to mention the large number of tribes whom the U.S. 
government either declined to recognize originally or for whom recognition was "terminated." With such diversity, no single study can adequately represent this group as a whole. Nonetheless, we believe this project is an important first step. These two samples were thoughtfully chosen to capture some of the diversity found among older American Indians. For instance, those in the Northern Plains sample reside in a highly rural reservation that is the sovereign nation of one tribe; indeed, about one third of American Indians live in reservation communities. On the other hand, the South Central sample is reflective of the increasingly urban nature of Native America in a different region of the country.

Both samples were recruited through word-of-mouth and snowball sampling in community organizations and may not be fully representative of elders in general, especially because abused elders may be less likely to engage with senior centers or churches. The only significant difference between the samples is employment status, with the Northern Plains participants more likely than South Central to be employed. Several factors may account for this, including the tendency for employed individuals on the reservation to continue working as long possible due to lack of sufficient retirement benefits and the ongoing need to support younger family members. Additionally, it is possible that some of these employed Northern Plains elders were benefiting from a state-funded program that offered part-time employment to seniors for 2 years.

In the end, although not fully representative of either American Indian elders nationally nor perhaps of the elders in these particular communities, this study provides essential data on both the performance of these elder mistreatment measures as well as some preliminary prevalence data on an issue that tribal leaders, elder advocates, and communities themselves agree is a high priority. It is important to acknowledge that reports of mistreatment in this study are likely underestimates. Because of institutional review board requirements, potential participants were informed three times that serious abuse would be reported to elder protective services, which undoubtedly could make mistreated participants hesitant to be interviewed or to reveal abuse. Nonetheless, only 15 potential participants declined to participate in the study.

Inclusion of these two, quite different, American Indian elder samples allowed interesting sample commonalities and differences to surface. For instance, although those in the Northern Plains group was more likely to endorse many HS-EAST items and had higher mean scores than their South Central counterparts, sample differences were less common at the item level on both the NELS-Financial Exploitation or NELS-Neglect scales and mean scale differences were not found. At the same time, all three scales showed significant bivariate relationships with the MCS of the SF-12, with the HS-EAST and NELS-Neglect remaining significant multivariately and the NELS-Financial 
Exploitation marginally significant. Furthermore, the sample variable did not have a significant interaction in these regressions. Thus, one can conclude that at least two, if not all three, elder mistreatment variables demonstrate predictive validity with the MCS for both tribes. This raises the question of why the Northern Plains elder sample appeared to be somewhat more vulnerable to mistreatment as assessed by the HS-EAST than did the South Central sample. One possibility is that this is an artifact of sampling strategy (i.e., recruitment via a senior center in the Northern Plains vs. Indian churches for the South Central sample). The Northern Plains senior center included both senior housing and a senior meal program. Many elders served by these programs were intensively involved with their families; almost one-third were living with children below the age of 18 years. Perhaps some of these factors (or a combination thereof) were related to greater vulnerability to mistreatment. For instance, since excessive and coercive care of grandchildren was identified in the qualitative component of the study as a serious issue for Native elders, it is possible that the multigenerational living arrangements on the Northern Plains related in some way to these participants' greater vulnerability. How the relatively high rate of employment in this subsample-40\% - contributes is unclear, but the known possession of financial resources in a low socioeconomic status community could potentially make one a target of financial exploitation. In contrast, the South Central sample consisted of Protestant Indian church members who in general tended to be more self-reliant and less involved with their extended families. Very few reported living with or raising children, and only $14 \%$ were currently working. These factors may have decreased the risk of mistreatment. Also, cultural differences in either the exposure to such risk factors or the willingness to report them may be a factor.

In conclusion, important next steps in our research agenda are to increase the sample sizes for psychometric investigations such as this - both in terms of numbers of participants and also a greater number of sites with sample sizes allowing for confirmatory factor analytic approaches. Using the data collected as part of the current study, careful consideration of further adaptations to the wording of specific questions is a priority. "Known group" designs should be considered in which the ability of the HS-EAST and the NELS-Financial Exploitation and NELS-Neglect scales to differentiate between mistreated and well-treated elders is directly tested.

\section{Authors' Note}

The Shielding American Indian Elders Project Team includes David Baldridge, Connie Bremner, Dedra Buchwald, John Compton, William Foote, Julie Holden, Yvonne M. Jackson, Lisa James, Chebon Kernell, Crystal LoudHawk-Hedgepeth, Spero M. 
Manson, Traci McClellan, Lisa Nerenberg, Emily Matt Salois, William SconzertHall, Bessie Smith, Charlene Smith, and Gloria Tallbull.

\section{Acknowledgements}

The authors are grateful to the study participants, the reservation's tribal council, and the Indian churches that made this research possible.

\section{Declaration of Conflicting Interests}

The authors declared no potential conflicts of interest with respect to the research, authorship, and/or publication of this article.

\section{Funding}

This research was funded by a grant from the National Institute on Aging (NIA R21AG030686-01, Lori L. Jervis, PI).

\section{References}

Beals, J., Manson, S. M., Mitchell, C. M., \& Spicer, P., \& and the AI-SUPERPFP Team. (2003). Cultural specificity and comparison in psychiatric epidemiology: Walking the tightrope in American Indian research. Culture, Medicine and Psychiatry, 27, 259-289.

Beals, J., Welty, T. K., Mitchell, C. M., Rhoades, D. A., Yeh, J. L., Henderson, J. A., \& Buchwald, D. S. (2006). Different factor loadings for SF36: The Strong Heart Study and the National Survey of Functional Health Status. Journal of Clinical Epidemiology, 59, 208-215.

Benson, W. F., Nerenberg, L., \& Baldridge, D. (2004). Elder abuse in Indian Country: A review of the literature-research, policy, and practice (No. 90-AP-2144). Washington, DC: National Indian Council on Aging for the National Center on Elder Abuse.

Buchwald, D., Tomita, S., Ashton, S., Furman, R., \& Manson, S. M. (2000). Physical abuse of urban Native Americans. Journal of General Internal Medicine, 15, 562-564.

Bureau of Indian Affairs. (2009). Indian entities recognized and eligible to receive services from the United States Bureau of Indian Affairs. Washington, DC: Federal Register.

Carson, D. K. (1995). American Indian elder abuse: Risk and protective factors among the older Americans. Journal of Elder Abuse \& Neglect, 7(1), 17-39.

Holkup, P. A., Salois, E. M., Tripp-Reimer, T., \& Weinert, C. (2007). Drawing on wisdom from the past: An elder abuse intervention with tribal communities. The Gerontologist, 47, 248-254.

Hudson, M. F., Armachain, W. D., Beasley, C. M., \& Carlson, J. R. (1998). Elder abuse: Two Native American views. The Gerontologist, 38, 538-548. 
Hudson, M. F., \& Carlson, J. R. (1999). Elder abuse: Its meaning to Caucasians, African Americans, and Native Americans. In T. Tatara (Ed.), Understanding elder abuse in minority populations (pp. 187-204). Philadelphia, PA: Brunner/Mazel.

Hwalek, M. A., \& Sengstock, M. C. (1986). Assessing the probability of abuse of the elderly: Toward development of a clinical screening instrument. Journal of Applied Gerontology, 5, 153-173.

IBM. (2010). IBM SPSS statistics (Version 19). Somers, NY: Author.

Jervis, L. L., \& and the Shielding American Indian Elders Project Team. (2009). Native elder mistreatment: A CBPR approach. Anthropology News, 50(4), 52-53. Jones, L., \& Wells, K. (2007). Strategies for academic and clinician engagement in community-participatory partnered research. Journal of the American Medical Association, 297, 407-410. doi:10.1001/jama.297.4.407

Minkler, M., Blackwell, A. G., Thompson, M., \& Tamir, H. (2003). Communitybased participatory research: Implications for public health funding. American Journal of Public Health, 93, 1210-1213.

Moody, L. E., Voss, A., \& Lengacher, C. A. (2000). Assessing abuse among the elderly living in public housing. Journal of Nursing Measurement, 8, 61-70.

Moon, A. (2000). Perceptions of elder abuse among various cultural groups: Similarities and differences. Generations, 24(2), 75.

Moon, A., \& Williams, O. (1993). Perceptions of elder abuse and help-seeking patterns among African-American, Caucasian-American, and Korean-American elderly women. The Gerontologist, 33, 386-395.

Moulton, C. P., Larme, A. C., Alford, C. L., Talamantes, M. A., McCorkle, R. J., \& Burge, S. K. (2005). Multiethnic perspectives on elder mistreatment. Journal of Elder Abuse \& Neglect, 17(2), 21-44.

Neale, A. V., Hwalek, M. A., Scott, R. D., Sengstock, M. C., \& Stahl, C. (1990). Validation of the Hwalek-Sengstock Elder Abuse Screening Test. Paper presented at the Gerontolological Society, Boston, MA.

Neale, A. V., Hwalek, M. A., Scott, R. O., Sengstock, M. C., \& Stahl, C. (1991). Validation of the Hwalek-Sengstock Elder Abuse Screening Test. Journal of Applied Gerontology, 10, 406-418.

Nerenberg, L., Benson, W. F., \& Baldridge, D. (2004). Preventing and responding to abuse of elders in Indian Country. Washington, DC: National Indian Council on Aging for the National Center on Elder Abuse.

Salois, E. M., Holkup, P. A., Tripp-Reimer, T., \& Weinert, C. (2006). Research as spiritual covenant. Western Journal of Nursing Research, 28, 505-524. doi: $10.1177 / 0193945906286809$

Schofield, M. J., \& Mishra, G. D. (2003). Validity of self-report screening scale for elder abuse: Women's health Australia study. The Gerontologist, 43(1), 110-120. 
Schofield, M. J., Reynolds, R., Mishra, G. D., Powers, J. R., \& Dobson, A. J. (2002). Screening for vulnerability to abuse among older women: Women's health Australia study. Journal of Applied Gerontology, 21, 24-39.

Simpson, A. R. (2005). Cultural issues and elder mistreatment. Clinics in Geriatric Medicine, 21, 355-364.

Talamantes, M. A., McCorkle, R. J., \& Burge, S. K. (2005). Multiethnic perspectives on elder mistreatment. Journal of Elder Abuse and Neglect, 7(2), 21-44.

Tatara, T. (1999). Understanding elder abuse in minority populations. Philadelphia, PA: Brunner/Mazel.

Wallerstein, N. B., \& Duran, B. (2006). Using community-based participatory research to address health disparities. Health Promotion Practice, 7, 312-323. doi: $10.1177 / 1524839906289376$

Ware, J. E. (1994). SF-36 Physical and Mental Health Summary Scales: A user's manual. Boston, MA: Health Institute, New England Medical Center.

\section{Author Biographies}

Lori L. Jervis, $\mathrm{PhD}$, is an Associate Professor in the Department of Anthropology and an Allied Director of the Center for Applied Social Research at the University of Oklahoma. Her research interests are in gerontology, psychiatric anthropology, trauma, and violence.

Alexandra Fickenscher, MPH, is a former Senior Professional Research Assistant in the Centers for American Indian and Alaska Native Health (CAIANH) at the Colorado School of Public Health, University of Colorado Denver.

Janette Beals, $\mathrm{PhD}$, is the Director of Research at the Centers for American Indian and Alaska Native Health (CAIANH) and a Professor at the Colorado School of Public Health at the University of Colorado Denver. With over 100 publications, she has written extensively about topics including: methodological issues, measure development, epidemiological descriptions of American Indian mental health/substance use, and descriptions of service use patterns in American Indian communities. 